\title{
Clinical efficacy and safety of magnetic sphincter augmentation (MSA) and transoral incisionless fundoplication (TIF2) in refractory gastroesophageal reflux disease (GERD): a systematic review and meta-analysis
}

\section{다 (우우}

\section{Authors}

Saurabh Chandan*, ${ }^{\text {, Babu P. Mohan*, }}{ }^{\text {, Shahab R. Khan }}{ }^{3}$, Lokesh K. Jha4, Amaninder J. Dhaliwal' ${ }^{1}$, Mohammad Bilal ${ }^{5}$, Muhammad Aziz ${ }^{6}$, Andrew Canakis ${ }^{7}$, Sumant Arora ${ }^{8}$, Sarah Malik ${ }^{1}$, Lena L. Kassab ${ }^{9}$, Suresh Ponnada ${ }^{10}$, Ishfaq Bhat ${ }^{1}$, Alexander T. Hewlett ${ }^{1}$, Neil Sharma ${ }^{5}$, Stephanie McDonough ${ }^{2}$, Douglas G. Adler ${ }^{2}$

Institutions

1 Division of Gastroenterology and Hepatology, $\mathrm{CHI}$ Creighton University Medical Center, Omaha, Nebraska, United States

2 Division of Gastroenterology and Hepatology, University of Utah School of Medicine, Salt Lake City, Utah, United States

3 Department of Medicine, Brigham and Women's Hospital, Boston, Massachusetts, United States

4 Gastroenterology, Parkview Health, Fort Wayne, Indianapolis, United States

5 Gastroenterology, Beth Israel Deaconess Medical Center, Boston, Massachusetts, United States

6 Internal Medicine, University of Toledo, Toledo, Ohio, United States

7 Internal Medicine, Boston University Medical Center, Boston, Massachusetts, United States

8 Gastroenterology \& Hepatology, University of lowa, lowa City, lowa, United States

9 Internal Medicine, Mayo Clinic, Rochester, Minnesota, United States

10 Internal Medicine, Carilion Roanoke Memorial Hospital, Roanoke, Virginia, United States

submitted 21.7.2020

accepted after revision 9.12.2020

Bibliography

Endosc Int Open 2021; 09: E583-E598

DOI 10.1055/a-1352-2944

ISSN 2364-3722

(C) 2021. The Author(s).

This is an open access article published by Thieme under the terms of the Creative Commons Attribution-NonDerivative-NonCommercial License, permitting copying and reproduction so long as the original work is given appropriate credit. Contents may not be used for commercial purposes, or adapted, remixed, transformed or built upon. (https://creativecommons.org/licenses/by-nc-nd/4.0/)
Georg Thieme Verlag KG, Rüdigerstraße 14,

70469 Stuttgart, Germany

Corresponding author

Douglas G. Adler MD, FACG, AGAF, FASGE, Professor of Medicine, Director of Therapeutic Endoscopy, Director, GI fellowship Program, Gastroenterology and Hepatology, University of Utah School of Medicine, Huntsman Cancer Center, 30N 1900E 4R118, Salt Lake City, Utah 84132, United States

Fax: +1-801-581-8007

Douglas.adler@hsc.utah.edu

\# Supplementary material is available under https://doi.org/10.1055/a-1352-2944

\section{ABSTRACT}

Background and study aims Proton pump inhibitors (PPI) are effective medical therapy options for gastroesophageal reflux disease (GERD). However, $20 \%$ to $40 \%$ of patients report symptoms despite taking daily PPI. Transoral incisionless fundoplication (TIF2) and magnetic sphincter augmentation (MSA) are less invasive options for the treatment of refractory GERD and are increasingly gaining popularity.

Methods We conducted a comprehensive search of several databases to identify relevant studies. Our primary aim was to compare the efficacy of both interventions reported as improvement in Gastroesophageal Reflux Disease-Health Related Quality of Life (GERD-HRQL) score, overall patient satisfaction, improvement in post-procedure regurgitation, and fraction of patients completely off PPI therapy at follow up.

Results Twenty-four studies with 1942 patients were included in the final analysis. Both MSA and TIF2 had comparable technical success and clinical success based on im-

\footnotetext{
* These authors contributed equally.
} 
provement in GERD-HRQL scores i.e. 98.8\% (Cl 95.6,99.7) vs $98.5 \%(\mathrm{Cl} 95.7,99.5)$ and $80.4 \%(\mathrm{Cl} 66,89.6)$ vs $77.7 \%$ (Cl 64.1,87.2), respectively. A significantly greater proportion of patients reported improvement in regurgitation, i.e. $91.1 \%(\mathrm{Cl} 83.8,95.3)$ vs $73.1 \%(\mathrm{Cl} 62.5,81.7)$ and were able to completely discontinue PPI therapy with MSA compared to TIF2 i.e. $91.3 \%(\mathrm{Cl} 81.5,96.2)$ vs $63.8 \%(\mathrm{Cl}$
51.6,74.4). Patients' BMI and presence of a hiatal hernia did not have any effect on procedural outcomes.

Conclusion Both procedures performed at par when comparing clinical success in terms of improvement in GERDHRQL scores. In terms of overall patient satisfaction, post procedure regurgitation and cumulative number of patients off PPI therapy, MSA outperforms TIF2.

\section{Introduction}

An estimated 9 million visits to the primary care physician are attributed to gastroesophageal reflux disease (GERD) and when severe, this condition can significantly impair a person's quality of life [1]. Treatment with proton pump inhibitor (PPI) therapy has been the mainstay of medical therapy for decades. Although most patients with acid reflux respond satisfactorily to PPI therapy, $20 \%$ to $42 \%$ may be considered "difficult to treat" [2-4]. While cheap and generally safe, there have been some concerns with PPI therapy, including increased infectious complications, nutritional deficiencies, as well as a potential risk of osteoporosis and dementia with long term use [5].

Patients who fail medical therapy or those who are referred to as having "refractory" GERD are often considered for anti-reflux surgery (which can be performed either via open or laparoscopic surgery or endoscopically). Surgical fundoplication is a highly efficacious procedure and remains the current gold standard in the surgical management of GERD [6]. Unlike PPI therapy, surgically manipulating the lower esophageal sphincter (LES) significantly reduces the number of reflux events, rather than merely reducing the acidity of the refluxate [7]. Traditional surgical fundoplication can at times result in complications such as postoperative dysphagia, recurrent heartburn and wrap disruption [8-10].

To help circumvent these complications, magnetic sphincter augmentation (MSA) with the LINX device (Torax Medical) was approved by the US Food and Drug Administration in 2012 for patients with mild to moderate GERD. This device is composed of a string of beads containing a sealed core of magnetic neodymium iron boride, which are interlinked with independent titanium wires. These magnets produce a very precise force of inward attraction ( $\sim 40 \mathrm{~g}$ at full contraction, $7 \mathrm{~g}$ at full expansion), which augments the closure of the lower esophageal sphincter. The beads are interconnected by small mobile wires that allow the device to expand so as to permit the passage of a food bolus as well as physiologic functions like belching or vomiting [11].

Transoral Incisionless Fundoplication (TIF) was first introduced in 2007. The procedure involves tissue manipulation using an endoscopic suturing device called EsophyX (Endogastric Solutions, Redmond, Washington, United States). TIF attempts to restore competency to the LES, preventing reflux of gastric contents. Eligible candidates include those with intractable reflux symptoms, no or mild esophagitis with hiatal hernia $<2 \mathrm{~cm}$ in length and abnormal acid reflux $[12,13]$.
While there have been several studies reporting clinical success and safety profile for both MSA and TIF, no randomized controlled trials have directly compared the two interventions. The goal of this study was to evaluate the clinical outcomes of these procedures, reported as improvement in cumulative GERD Health-Related Quality of Life (GERD-HRQL) scores, patient reported symptom improvement, and overall patient reported satisfaction as well as total number of patients off PPI therapy at maximum follow up, by meta-analysis methods.

\section{Methods}

\section{Search strategy}

The literature was searched by a medical librarian for studies that reported on the use of magnetic sphincter augmentation (MSA) and trans-oral fundoplication (TIF) in the treatment of gastroesophageal reflux disease (GERD). Searches were run in December 2019 in ClinicalTrials.gov, Ovid EBM Reviews, Ovid Embase $(1974+)$, Ovid Medline $(1946+$ including epub ahead of print, in-process \& other non-indexed citations), Scopus $(1970+)$ and Web of Science $(1975+)$. Results were limited to English language. All results were exported to Endnote where 815 obvious duplicates were removed leaving 869 citations. The full search strategy is available in Supplementary Appendix 1. The MOOSE checklist was followed and is provided as Supplementary Appendix 2 [14]. Reference lists of evaluated studies were examined to identify other studies of interest.

\section{Study selection}

In this meta-analysis, we included studies that evaluated the clinical outcomes of MSA and TIF in patients undergoing treatment for refractory GERD. Studies were included irrespective of inpatient/outpatient setting, study sample-size, follow-up time, and geography as long as they provided the clinical outcomes data needed for the analysis.

Our exclusion criteria were as follows: (1) studies that evaluated TIF1 procedure; (2) studies where TIF was performed with concurrent hiatal hernia repair [15-17]; (3) studies where MSA was performed with concurrent hiatal hernia repair [1820]; (4) studies that did not report on the clinical outcomes of interest; (5) studies performed in the pediatric population (Age $<18$ years); and (6) studies not published in English language. In cases of multiple publications from a single research group reporting on the same patient, same cohort and/or overlapping cohorts, data from the most recent and/or most appropriate comprehensive report were retained. The retained studies 
were selected by two authors (BPM, SC) based on the publication timing (most recent) and/ or the sample size of the study (largest). In situations where a consensus could not be reached, overlapping studies were included in the final analysis and any potential effects were assessed by sensitivity analysis of the pooled outcomes by leaving out one study at a time.

\section{Data abstraction and quality assessment}

Data on study-related outcomes from the individual studies were abstracted independently onto a standardized form by at least four authors (BPM, SRK, SC, MB). Authors (SC, LLK, LKJ and $\mathrm{SA})$ cross-verified the collected data for possible errors and two authors (BPM, SC) did the quality scoring independently.

The Newcastle-Ottawa scale for cohort studies was used to assess the quality of studies [21]. This quality score consisted of eight questions, the details of which are provided in Supplementary Table 1.

\section{Outcomes assessed}

The outcomes assessed were as follows:

1. Pooled rates of clinical success as determined by $>50 \% \mathrm{im}$ provement in cumulative GERD-HRQL score

2. Pooled rate of clinical success as determined by patient satisfaction (per Alimentary Satisfaction (AS) score [22] or reported as "Dissatisfied, Neutral, Satisfied" [23-25] at followup

3. Pooled rate of clinical success as determined by percentage of patients

reporting improvement in regurgitation at follow up as determined by Reflux Disease Questionnaire (RDQ) [26-28], Foregut Symptom Questionnaire (FSQ) [29,30], Regurgitation Score [23, 24, 31]

1. Pooled rate of number of patients completely off PPI therapy at follow up

2. Pooled rates of technical success of MSA and TIF2

3. Pooled rate of post-procedural dysphagia

4. Meta-regression analysis to assess effect of BMI on outcomes of in both study

5. cohorts

6. Meta-regression analysis to assess the effect of presence of pre-procedure

hiatal hernia on clinical success in both study cohorts

\section{Assessment methodology and definitions}

The collected data were matched between the groups (MSA, TIF2) before statistical analysis. Comparison analysis was performed by sub-group analysis between the pooled outcomes of MSA and TIF2. This model of comparison is comparable to a retrospective case-control study with matched groups and should be considered non-causal [32].

\section{Statistical analysis}

We used meta-analysis techniques to calculate the pooled estimates in each case following the methods suggested by DerSimonian and Laird using the random-effects model [33]. When the incidence of an outcome was zero in a study, a continuity correction of 0.5 was added to the number of incident cases before statistical analysis [34].

We assessed heterogeneity between study-specific estimates by using Cochran Q statistical test for heterogeneity, $95 \%$ prediction interval $(\mathrm{PI})$, which deals with the dispersion of the effects, and the $I^{2}$ statistics. $[35,36]$ In this, values of $<30 \%, 30 \%$ to $60 \%, 61 \%$ to $75 \%$, and $>75 \%$ were suggestive of low, moderate, substantial, and considerable heterogeneity, respectively.

Publication bias was ascertained, qualitatively, by visual inspection of funnel plot and quantitatively, by the Egger test [37]. When publication bias was present, further statistics using the fail-Safe $\mathrm{N}$ test and Duval and Tweedie's 'Trim and Fill' test was used to ascertain the impact of the bias [38]. Three levels of impact were reported based on the concordance between the reported results and the actual estimate if there were no bias. The impact was reported as minimal if both versions were estimated to be same, modest if effect size changed substantially but the final finding would still remain the same, and severe if basic final conclusion of the analysis is threatened by the bias [39]. $P<0.05$ was used a-priori to define significance between the groups compared.

When possible, meta-regression analysis was carried out to study the effects of clinical variables on pooled outcomes. Single variable analysis was done assuming other variables to be constant using a random-effects model. A Knapp-Hartung 2tailed $P<0.05$ was considered statistically significant.

All analyses were performed using Comprehensive Meta-Analysis (CMA) software, version 3 (BioStat, Englewood, New Jersey, United States).

\section{Results}

\section{Search results and population characteristics}

From an initial pool of 1684 studies, 869 records were screened and 64 full-length articles were assessed. A total of 24 studies (1942 patients) were included in the analysis. 1074 patients (566 males, 508 females) underwent treatment with MSA (9 studies) and 868 patients (379 males, 489 females) underwent treatment with TIF2 (15 studies).

The schematic diagram demonstrating our study selection is illustrated in Supplementary Fig. 1. Baseline population characteristics were comparable between the MSA and TIF2 cohorts. The mean and/or median age ranged from 44 to 63 years in the MSA cohort and 36 to 68 years in the TIF2 cohort. The mean duration of GERD pre-treatment ranged from 5 to 14.2 years in the MSA cohort and 5 to 11.2 years in the TIF2 cohort. A total of 389 patients in the MSA cohort and 462 patients in the TIF2 cohort had hiatal hernias. In the TIF2 group, 158 patients had a Hill Grade III/IV hiatal hernia. Further details along with the population characteristics are described in $>$ Table $1 \mathbf{a}$, - Table $1 \mathrm{~b}$ and $>$ Table 2. 


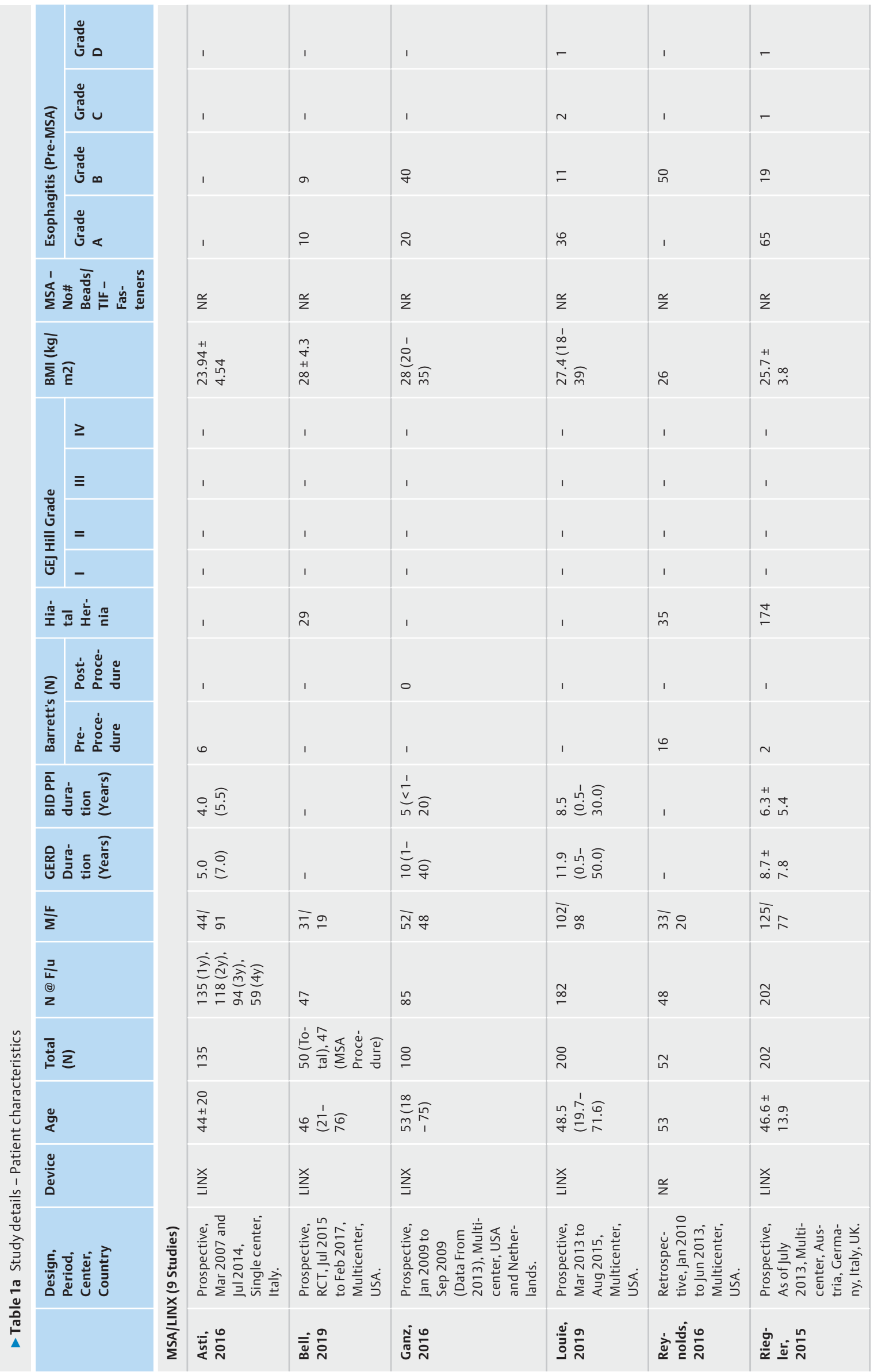




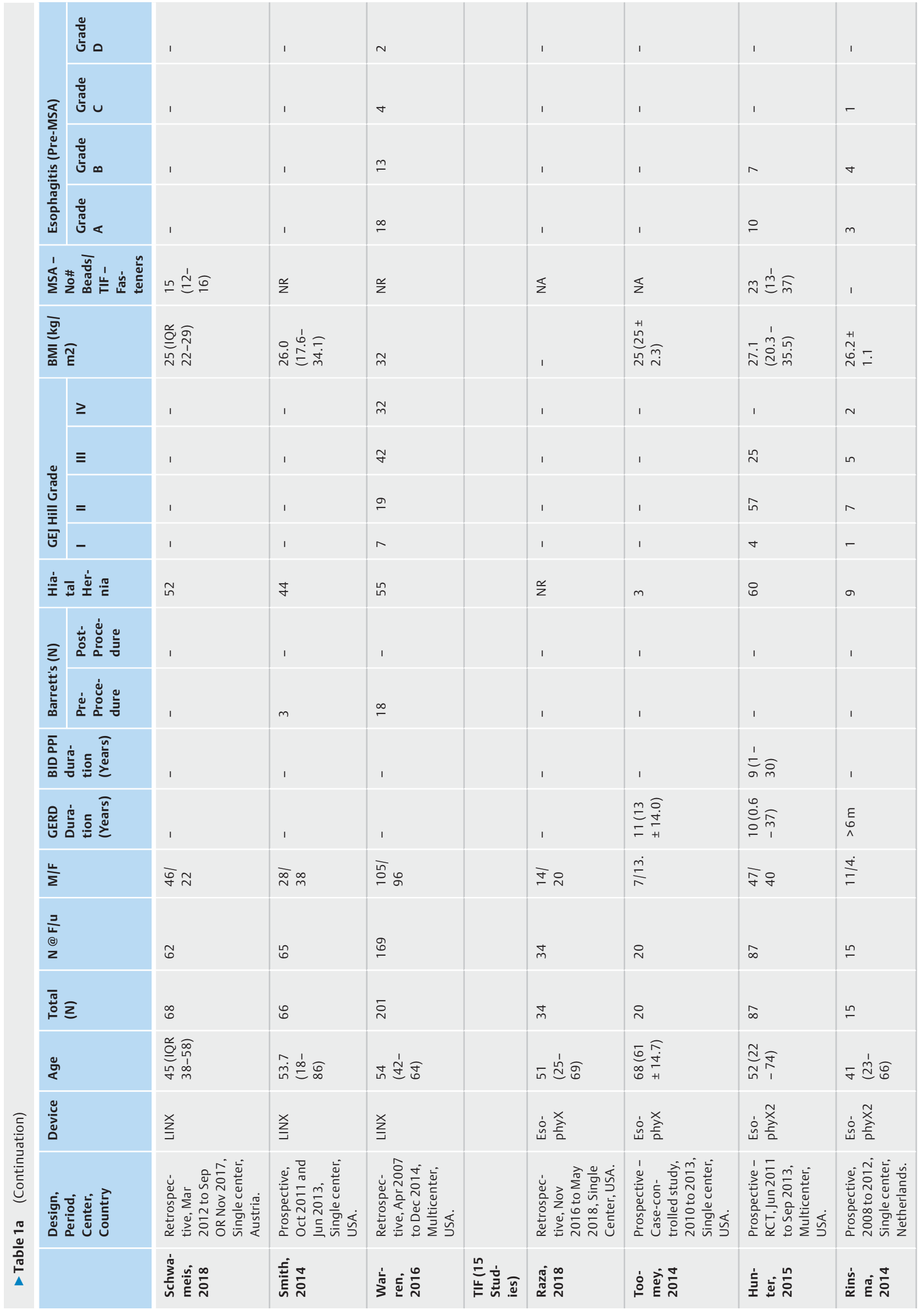


Review

Thieme

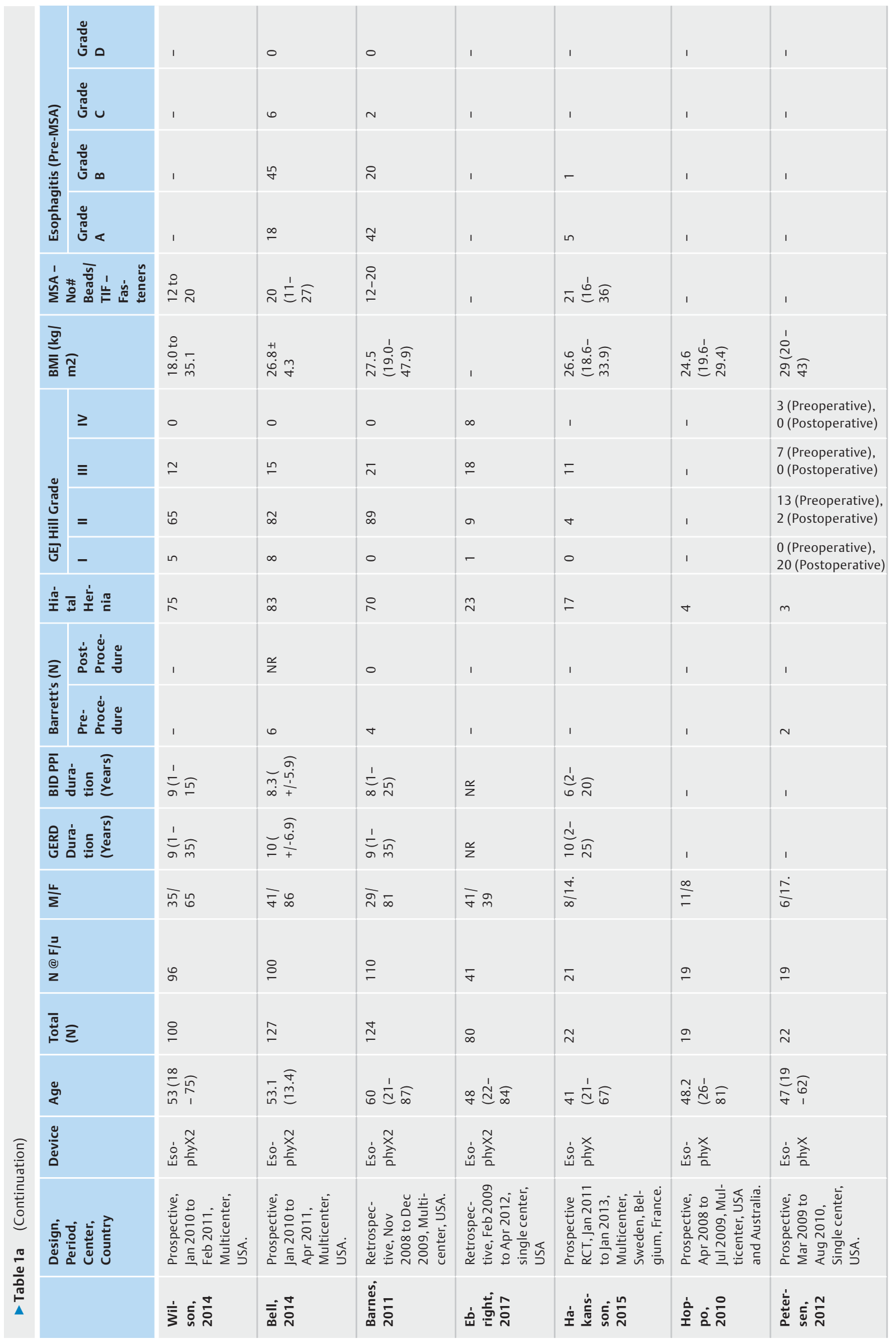

E588

Chandan Saurabh et al. Clinical efficacy and ... Endosc Int Open 2021; 09: E583-E598 | ® 2021. The Author(s). 


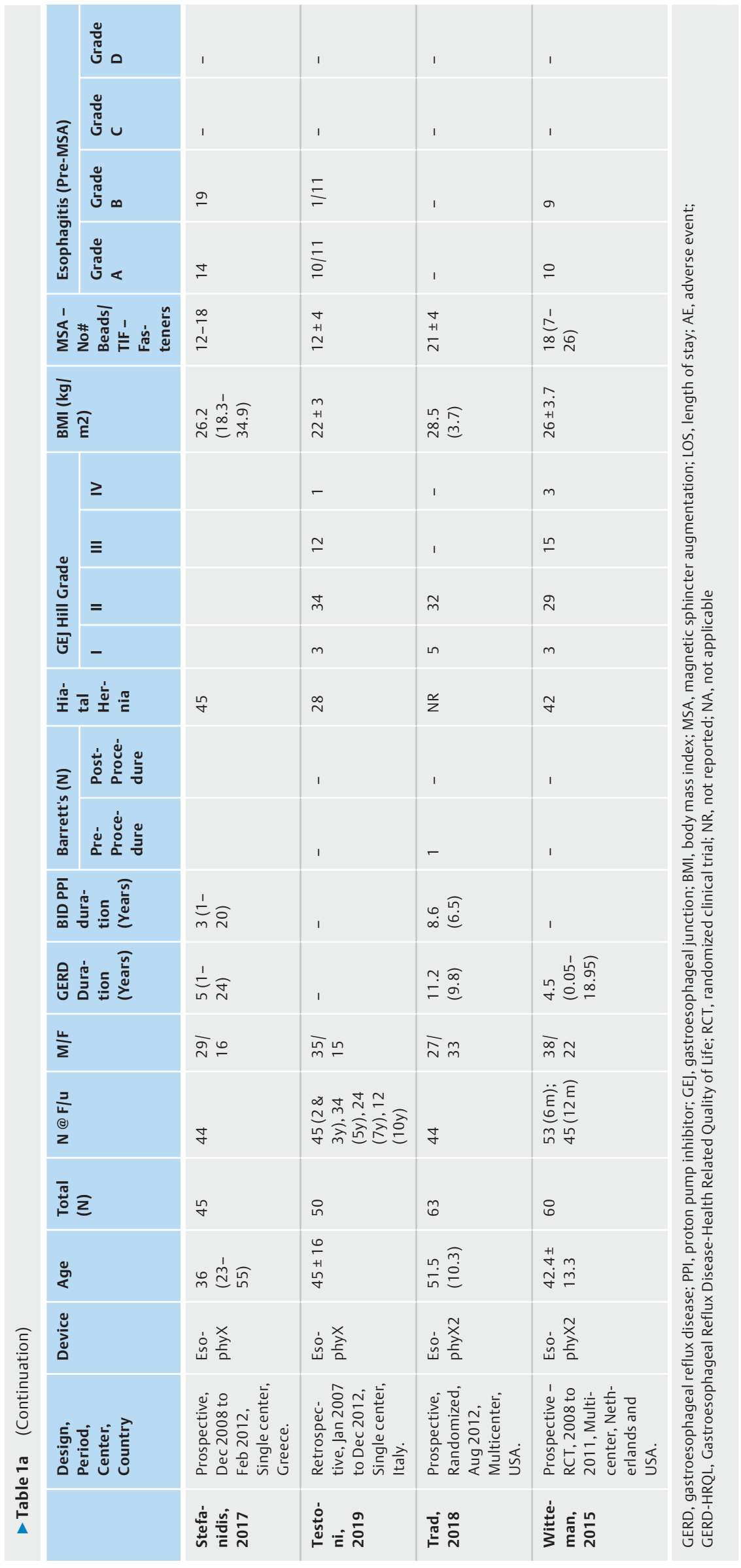




\section{$\frac{2}{2 n}$}

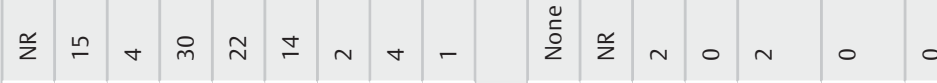

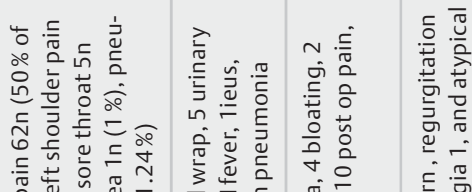

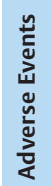

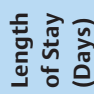

0 - 000 - 000 -

o 0 in 0 - 0

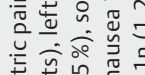

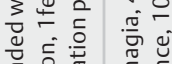

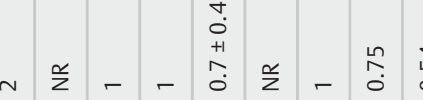

-

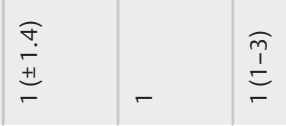

In

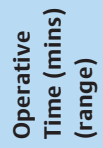

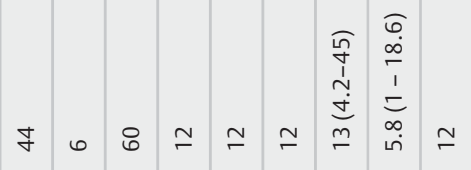

立辛。

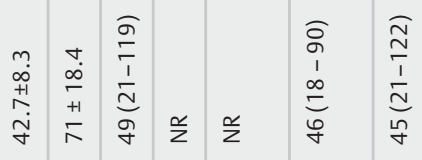

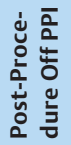

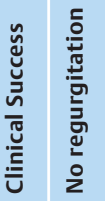

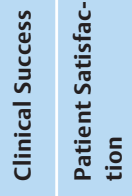

部

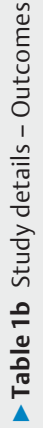

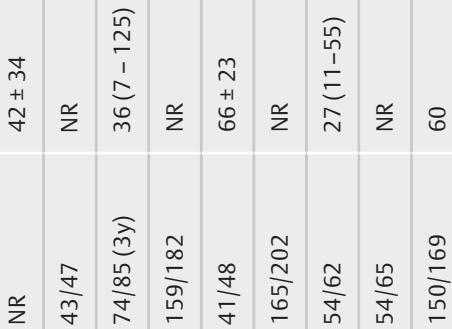

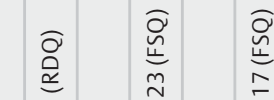

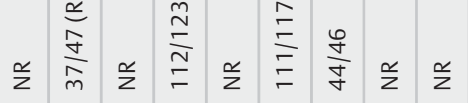

$\frac{\sqrt{2}}{\sqrt[n]{5}}$

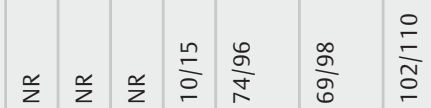

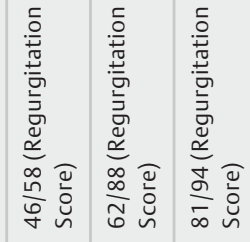

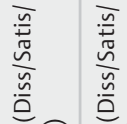

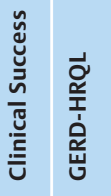

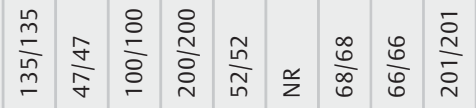

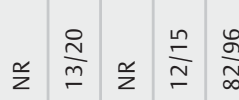

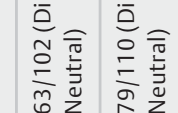

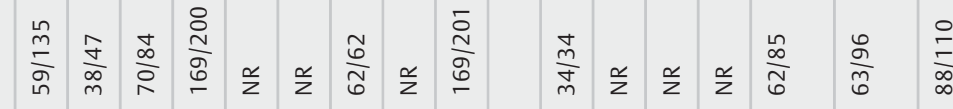
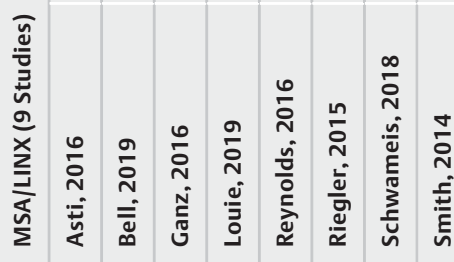

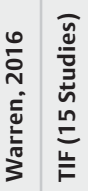

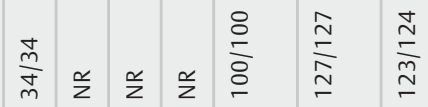

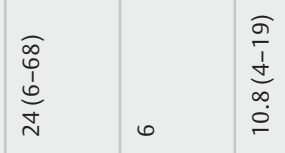

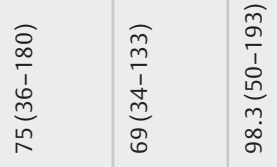

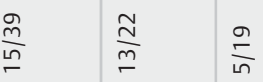

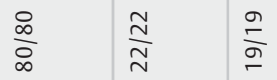




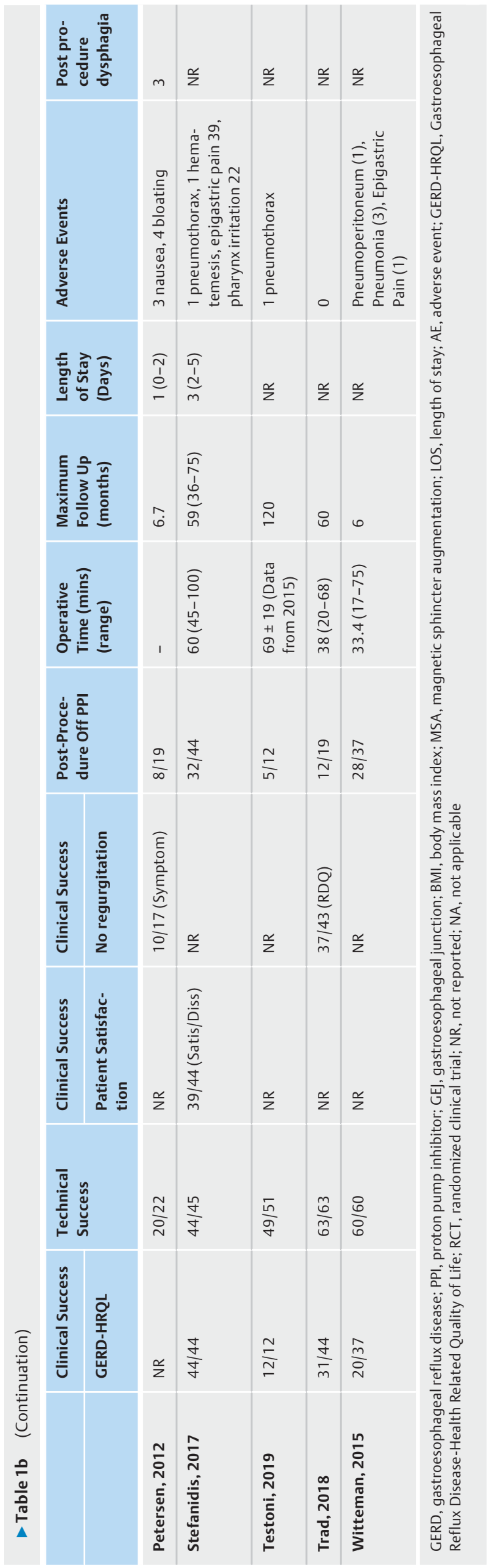

\section{Characteristics and quality of included studies}

In the MSA cohort, six studies [26, 29, 30, 40-42] were prospective and three $[22,43,44]$ were retrospective, whereas in the TIF2 cohort, 11 studies were prospective $[23,25,27,28,31$, 45-50] and four were retrospective [24, 51-53]. There were no TIF or MSA studies based on population data. Based on the New-Castle Ottawa scoring system, all nine MSA studies [22, 26,29,30,40-44] were considered to be of high quality, 12 TIF studies were of high quality, and three TIF studies $[46,49,51]$ were of medium quality. There were no low-quality studies.

\section{Meta-analysis outcomes \\ Clinical success (measure of improvement in GERD HRQL score)}

The pooled rate of clinical success with MSA was $80.4 \%(95 \% \mathrm{Cl}$ : 66-89.6) and with TIF2 was $77.7 \%$ (95\% CI 64.1-87.2). The rates were not statistically significantly different (> Fig. 1). The pooled rate of clinical success with MSA in $\leq 12$ months followup ( 3 studies) was $83.3 \%(95 \% \mathrm{Cl} 65.3-93) ; \mathrm{I} 2=0$ and in $>12$ months follow-up was $75.9 \%$ (95\% Cl 50.8-90.5). The pooled rate of clinical success with TIF2 in $\leq 12$ months (4 studies) was $71.2 \%$ (95\% Cl 57.3-82); I2 = 67 and in $>12$ months (4 studies) was $76.1 \%$ (95\% Cl 59.6-87.3); I2=70. The rates were comparable.

\section{Clinical success (Overall patient satisfaction reported at follow up)}

The pooled rate of clinical success with MSA was $86.3 \%(95 \% \mathrm{Cl}$ 74.8-93.1) and with TIF2 was $72.5 \%$ (95\% CI 61.6-81.3). The rates were not statistically significantly different ( $\triangleright$ Fig. 2 ).

\section{Clinical success (Improvement in post procedure regurgitation symptoms at follow up)}

The pooled rate of clinical success with MSA was $91.1 \%(95 \% \mathrm{CI}$ 83.8-95.3) and with TIF2 was $73.1 \%$ (95\% CI 62.5-81.7). The difference between the cohorts was statistically significant $(P$ $=0.002)$ ( Fig. 3 ).

\section{Patients off PPI}

The pooled proportion of patients off PPI therapy with MSA was 86.5\% (95\% Cl 80.4-91) and with TIF2 was 64.4\% (95\% Cl 5572.8). Based on sub-group comparison MSA seemed to be significantly superior to TIF2 $(P=0.001)$ ( $\triangleright$ Fig. 4$)$.

\section{Technical success}

The pooled rate of technical success for MSA was $98.8 \%(95 \% \mathrm{Cl}$ 95.6-99.7) and for TIF2 was 98.5\% (95\% CI 95.7-99.5) (Supplementary Fig. 2).

\section{Post-procedure dysphagia}

The pooled rate of dysphagia with MSA was $9.1 \%$ (95\% Cl 4.2$18.8)$ and with TIF was $3.6 \%(95 \% \mathrm{Cl} 1.4-8.8)$. Although greater, the $P$ value was non-significant $(P=0.05)$ (Supplementary Fig. 3). 


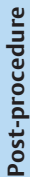

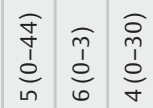

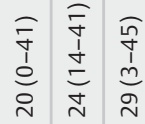

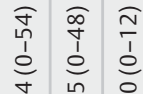

产

高

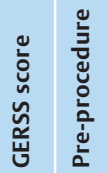

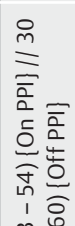

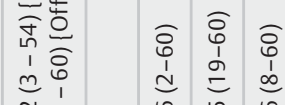

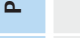

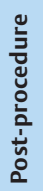

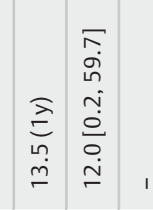

1 $\approx$ ㄴ.

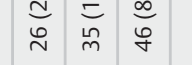

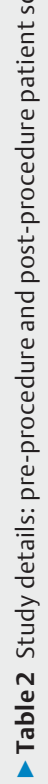

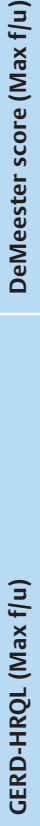

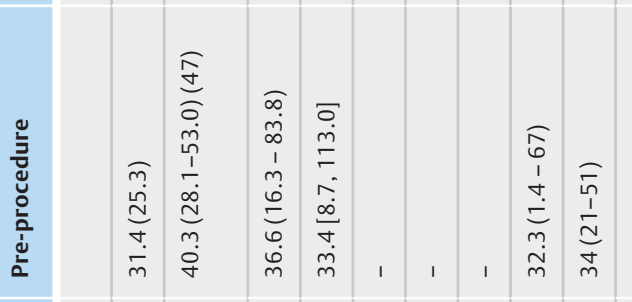

这

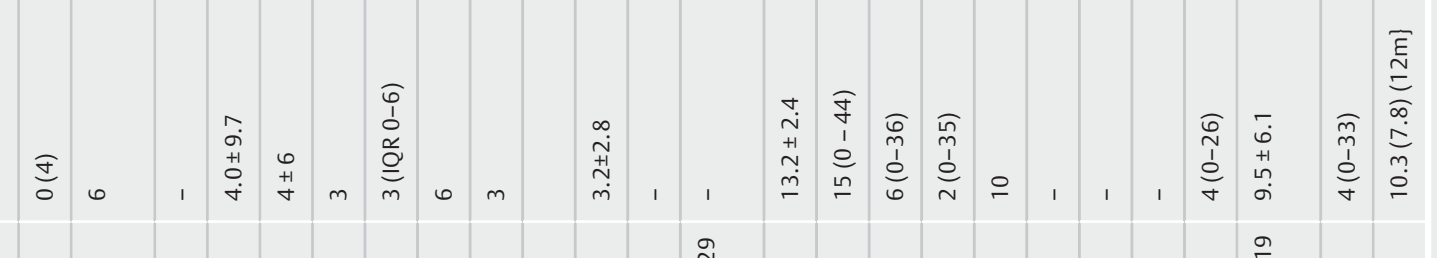

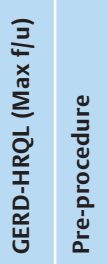

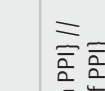
ธิด

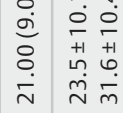

$\stackrel{\text { }}{\stackrel{\overline{\bar{z}}}{\overline{2}}}$

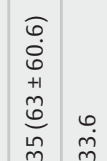

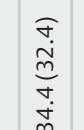

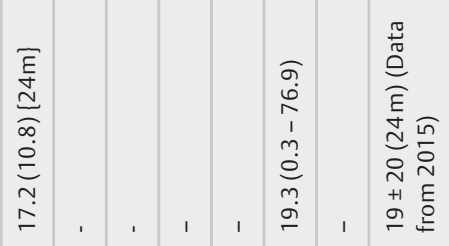
$\stackrel{\sim}{N}$, 


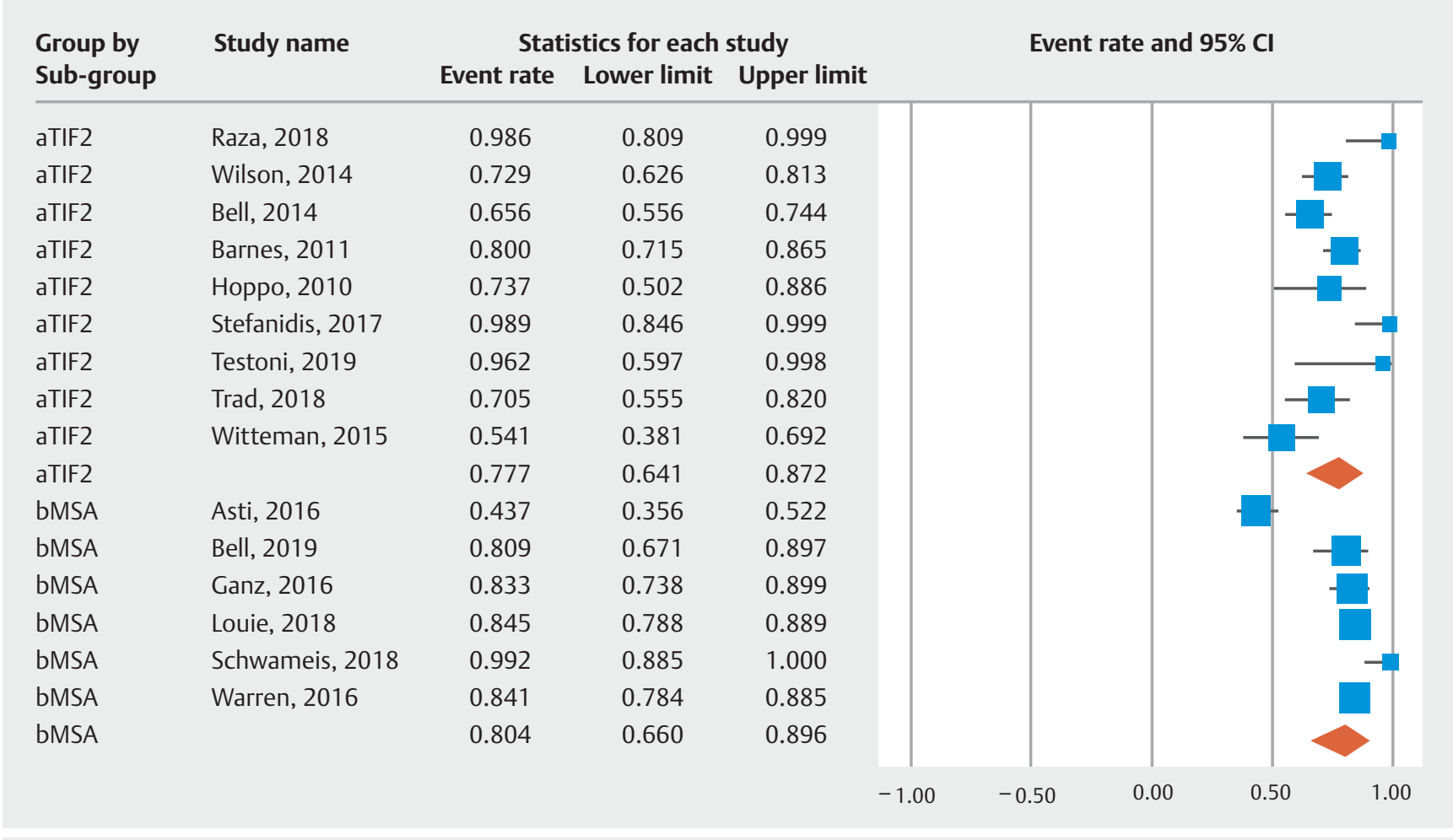

- Fig. 1 Forest plot of clinical success (GERD-HRQL).

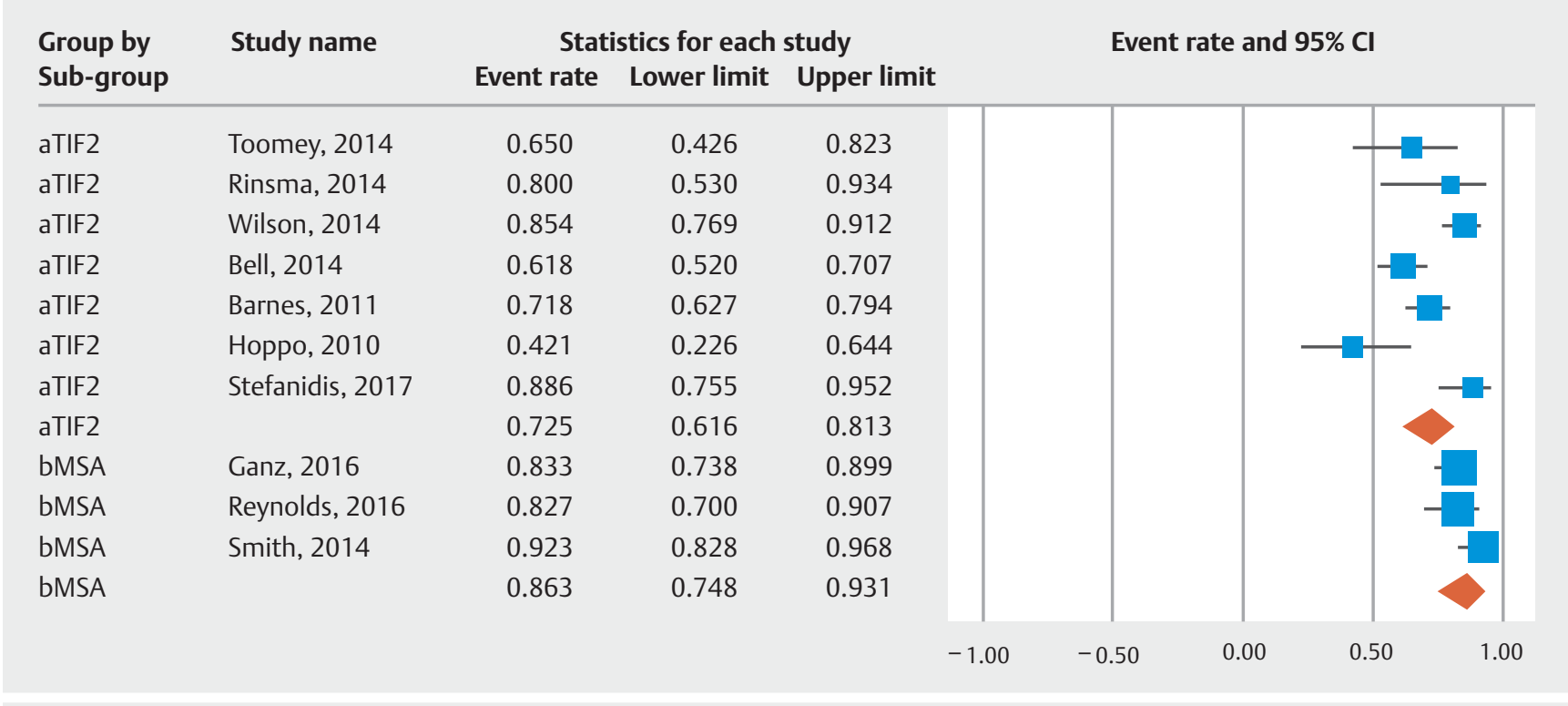

- Fig. 2 Forest plot of clinical success (patient satisfaction).

\section{Meta-regression analysis}

Patient variables that were amenable to meta-regression analysis were as follows: Patient BMI and presence of hiatal hernia. BMI did not have any statistically significant effect on outcomes of TIF2 $(P=0.7)$ or MSA $(P=0.1)$. Also, the presence of hiatal hernia did not affect clinical success in either of the two study cohorts (Supplementary Fig.4).

\section{Validation of meta-analysis results}

Sensitivity analysis

To assess whether any one study had a dominant effect on the meta-analysis, we excluded one study at a time and analyzed its effect on the main summary estimate. In this analysis, no single study significantly affected the outcome or the heterogeneity. 


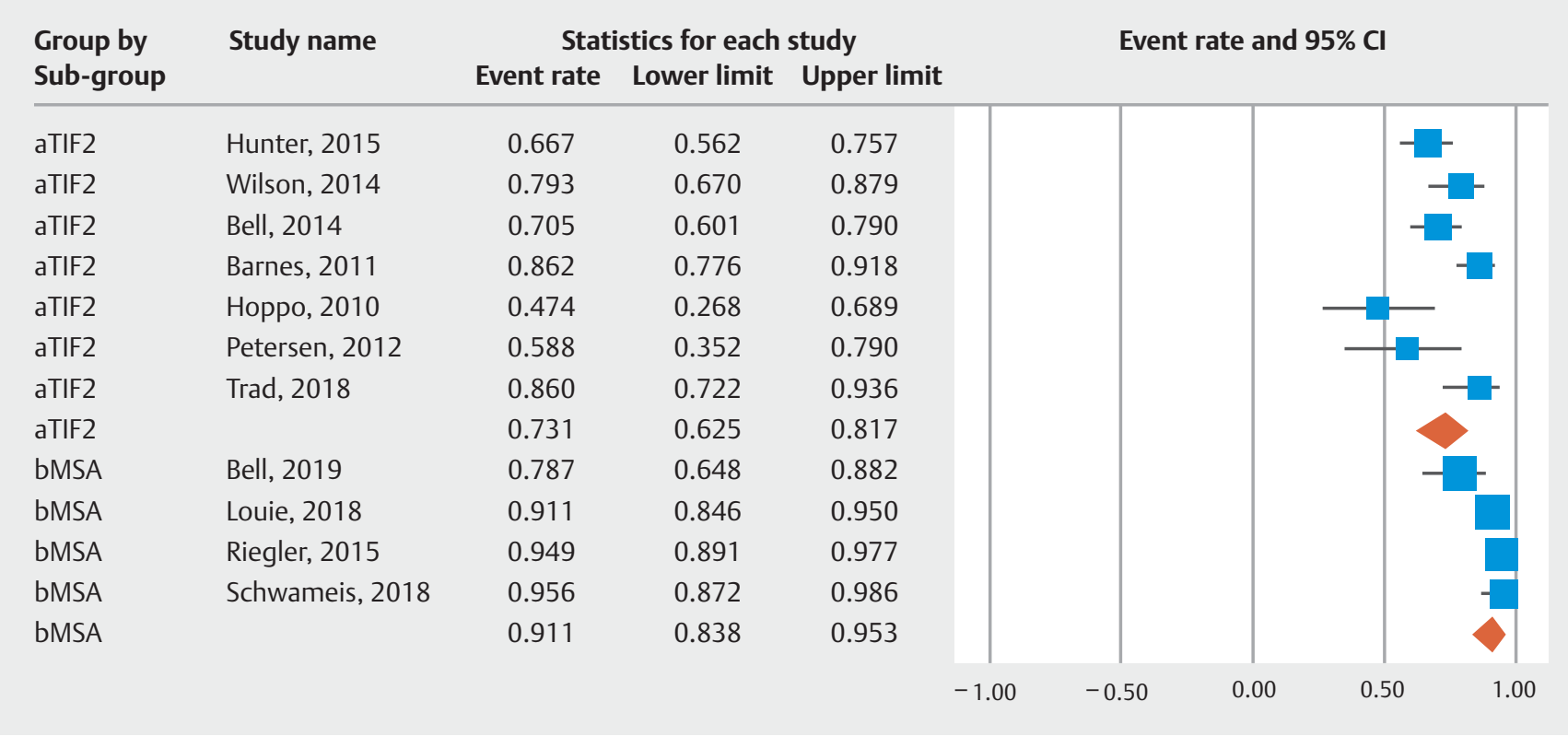

- Fig. 3 Forest plot of clinical success (regurgitation).

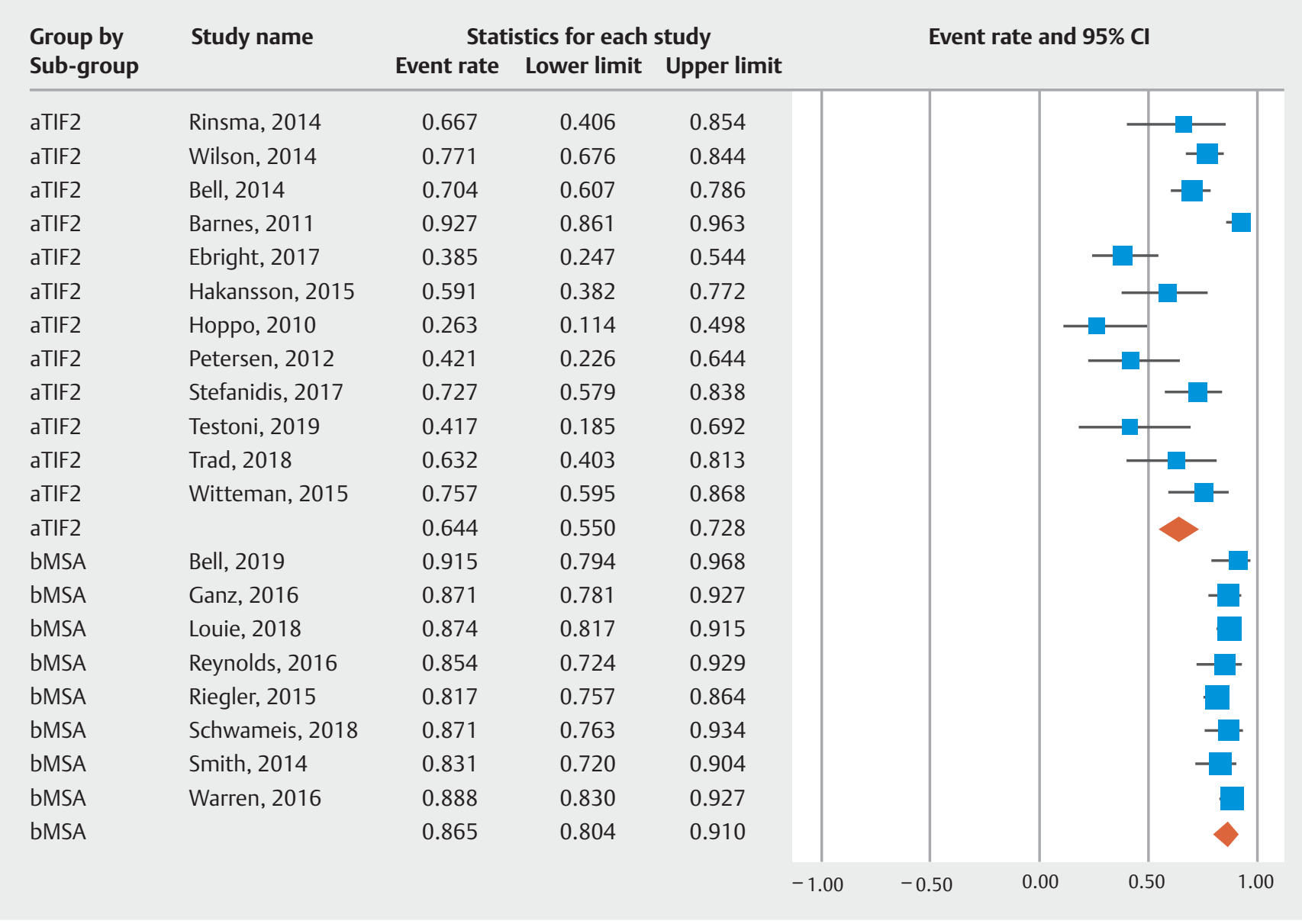

- Fig. 4 Forest plot of patients off PPI therapy at follow-up. 
Table 3 Pooled rates of outcomes with $\mathrm{Cl}$ and PI.

\begin{tabular}{|c|c|c|}
\hline & \multicolumn{2}{|c|}{ Pooled rates ( $95 \%$ confidence interval) 12 heterogeneity \% } \\
\hline & MSA & TIF2 \\
\hline $\begin{array}{l}\text { Clinical success } \\
\text { (GERD HRQL) }\end{array}$ & $\begin{array}{l}80.4 \%(66-89.6) ; \\
6 \text { studies }(P=0.8) \\
12=94 ; \text { PI: } 23 \text { to } 98 \\
\leq 12 \text { months }(3 \text { studies }) \\
83.3 \%(65.3-93) ; 12=0 \\
>12 \text { months }(3 \text { studies }) \\
75.9 \%(50.8-90.5) ; 12=95\end{array}$ & $\begin{array}{l}77.7 \%(64.1-87.2) \\
9 \text { studies } \\
\text { I2 = } 68 ; \text { PI: } 48 \text { to } 95 \\
\leq 12 \text { months }(4 \text { studies) } \\
71.2 \% \text { ( } 57.3-82) ; 12=67 \\
>12 \text { months }(4 \text { studies) } \\
76.1 \% \text { (59.6-87.3); } 12=70\end{array}$ \\
\hline $\begin{array}{l}\text { Clinical success } \\
\text { (patient satisfaction) }\end{array}$ & $\begin{array}{l}86.3 \%(74.8-93.1) \\
3 \text { studies }(P=0.06) \\
12=2 ; P I: 61 \text { to } 96\end{array}$ & $\begin{array}{l}72.5 \%(61.6-81.3) \\
7 \text { studies } \\
\text { I2 = } 75 ; \text { PI: } 41 \text { to } 92\end{array}$ \\
\hline $\begin{array}{l}\text { Clinical success } \\
\text { (no regurgitation) }\end{array}$ & $\begin{array}{l}91.1 \%(83.8-95.3) \\
4 \text { studies }(P=0.002) \\
\text { I2 = 68; PI: } 56 \text { to } 99\end{array}$ & $\begin{array}{l}73.1 \% \text { ( } 62.5-81.7) ; \\
7 \text { studies } \\
\text { I2 = 68; PI: } 44 \text { to } 91\end{array}$ \\
\hline Patients off PPI at follow-up & $\begin{array}{l}86.5 \%(80.4-91) \\
8 \text { studies }(P=0.001) \\
\text { I2 = } 0 ; P I: 78 \text { to } 92\end{array}$ & $\begin{array}{l}64.4 \%(55-72.8) \\
12 \text { studies } \\
\text { I2= 80; PI: } 28 \text { to } 91\end{array}$ \\
\hline Technical success & $\begin{array}{l}98.8 \%(95.6-99.7) \\
11 \text { studies }(P=0.5) \\
12=81 ; P I: 38 \text { to } 99\end{array}$ & $\begin{array}{l}98.5 \% \text { (95.7-99.5); } \\
8 \text { studies } \\
\text { I2 = 0; PI: } 90 \text { to } 99\end{array}$ \\
\hline Postoperative dysphagia & $\begin{array}{l}9.1 \%(4.2-18.8) \\
8 \text { studies }(P=0.05) \\
I 2=89 ; P I: 1 \text { to } 50\end{array}$ & $\begin{array}{l}3.6 \%(1.4-8.8) \\
9 \text { studies } \\
\text { I2 = 58; PI: } 1 \text { to } 34\end{array}$ \\
\hline
\end{tabular}

MSA, magnetic sphincter augmentation; TIF, trans-oral fundoplication; GERD, gastroesophageal reflux disease; HRQL, health related quality of life; PI, 95\% prediction intervals; PPI, proton pump inhibitor.

\section{Heterogeneity}

We assessed dispersion of the calculated rates using the confidence interval $(\mathrm{Cl})$ and $\mathrm{I}^{2}$ percentage values. The $\mathrm{Cl}$ gives an idea of the range of the dispersion and $\mathrm{I}^{2}$ tells us what proportion of the dispersion is true vs chance [36]. The PIs are reported with the pooled rates in $>$ Table 3 . Overall, considerable heterogeneity was noted in the analysis.

\section{Publication bias}

Based on visual inspection of the funnel plot as well as quantitative measurement that used the Egger regression test, there was evidence of publication bias (Supplementary Fig.4, Eggers 2-tailed $P=0.01$ ). Further statistical analysis using the failSafe $N$ test and Duval and Tweedie's Trim and Fill test revealed that the reported pooled results would not be significantly affected by the unpublished studies.

\section{Discussion}

Magnetic sphincter augmentation (MSA) and trans-oral incisionless fundoplication (TIF2) demonstrate comparable efficacy when comparing improvement in cumulative GERD-HRQL scores at follow-up. When comparing outcomes in terms of, post procedure regurgitation and percentage of patients off PPI therapy at follow up, MSA significantly outperforms TIF2. To the best of our knowledge, this study is the first quantitative review presenting a comparison between MSA and TIF2 in the treatment of refractory GERD.
The Gastroesophageal Reflux Disease-Health Related Quality-of-Life (GERD-HRQL) scale is a disease-specific instrument, developed to help overcome the variability in evaluating response to treatments for GERD and has been validated as the only significant predictor of patient satisfaction. A total score is computed for the heartburn symptoms questions based on a scale of 0 to 5 , where $0=$ no symptoms and $5=$ incapacitation to do daily activities. A reduction of the score by $50 \%$ or greater is considered to indicate a successful intervention [54]. In our analysis, based on improvement in GERD-HRQL at longest follow up, pooled clinical success was $80.4 \%$ with MSA and $77.7 \%$ with TIF2 $(P=0.8)$.

In recent years, there has been a growing body of literature raising concerns about long term PPI use [5]. We found that the pooled percentage of patients who were able to completely stop PPI therapy after MSA was $91.3 \%$ compared to only $63.8 \%$ after undergoing TIF2 $(P=0.001)$. Given the variability in outcome reporting in the literature, we also factored in overall patient satisfaction that was comparable, and improvement in post-operative regurgitation as measures of clinical success, which was better with MSA.

TIF is associated with fewer postoperative adverse effects such as gas bloating and dysphagia when compared with surgical fundoplication [55]. Dysphagia is thought to be prominent post MSA implantation but generally resolves within a few weeks [41]. We compared post procedure dysphagia between the two study cohorts and demonstrated a non-significant greater rate with MSA (9.1\% vs $3.6 \%$; $P=0.05)$. Follow up period 
ranged from 5.8 to 60 months in the MSA cohort, and 6 to 120 months in the TIF2 cohort.

With regards to adverse events, LINX device was removed in 24 patients, most commonly due to postoperative GERD, chest pain and dysphagia. In the TIF2 cohort, postoperative epigastric pain was the most common adverse event, reported in 114 patients $(0.1 \%)$. Pneumothorax in two patients, pneumoperitoneum in 1 patient and postoperative pneumonia was reported in four patients. Ebright et al [52] reported six patients with a degraded wrap, five with urinary retention and one each with postoperative fever, ileus, and aspiration. Overall, there were 229 adverse events reported in the TIF2 cohort of patients.

In 2017, Huang et al, conducted a systematic review and meta-analysis of five randomized trials and 13 prospective studies and found that PPI use after TIF increased over time (albeit at a reduced dose) and the overall patient satisfaction rate was $69 \%$ at 6-month follow-up [2]. This study included results from the first and second (current) generation of TIF devices. While the first-generation device (TIF1) was commercially introduced in 2007, it was not until 2009 that the second generation of the device, TIF2, was made available. Our study included only those patients who underwent the TIF2 procedure.

In 2019, Guidozzi et al [56] conducted a systematic review and meta-analysis comparing MSA to laparoscopic fundoplication and concluded that the former achieves good GERD symptomatic control similar to that of fundoplication, with $3.3 \%$ of patients requiring device removal. Our study is the first in literature to compare MSA and TIF2 based on similar patient reported outcomes.

The strengths of this review are as follows: systematic literature search with well-defined inclusion criteria, careful exclusion of redundant studies, inclusion of good quality studies with detailed extraction of data and rigorous evaluation of study quality. We calculated not only pooled subjective outcomes based on patient reported clinical symptoms but also objective outcomes i.e. percentage of patients successfully able to stop PPI therapy. We utilized meta-regression analysis to evaluate the effect of pre procedural BMI and presence of hiatal hernia on clinical outcomes. Finally, we excluded all TIF2 and MSA studies where patients underwent concurrent hiatal hernia $(\mathrm{HH})$ repair. This is important because patients undergoing $\mathrm{HH}$ repair surgery have improved GERD-HRQL scores and can have post procedural side effects such as dysphagia [57].

There are limitations to this study as well, most of which are inherent to any meta-analysis. Our analysis had studies that were retrospective in nature contributing to selection bias. We compared outcomes based on improvement in GERD-HRQL score and used $\geq 50 \%$ improvement in score as a measure of clinical success. While this was the most consistently reported outcome in the included studies, it is possible that studies reporting $<50 \%$ improvement in GERD-HRQL score for either MSA or TIF2 were missed. While we were able to quantify the proportion of patients who discontinued PPI therapy at follow up, we were unable to objectively study this data in terms of post procedural $\mathrm{pH}$ testing data.

Manometry and impedance data were not consistently reported in all studies. Although we report meta-regression anal- ysis, it is important to note that meta-regression analysis is considered a weak statistic in the analysis of patient variables on pooled outcomes. Our analysis has the limitation of non-causal comparison and heterogeneity. Nevertheless, this study is the best available data in literature thus far with respect to the clinical outcomes of MSA and TIF2 in patients with refractory GERD.

\section{Conclusion}

In conclusion, MSA and TIF2 appear to have similar efficacy based on post procedure GERD-HRQL scores however MSA seems to significantly outperform TIF2 in terms of patient reported outcomes with long term follow up. Overall, $91.3 \%$ of patients were able to stop PPI therapy after MSA as compared to $63.8 \%$ after TIF2. Future well-conducted trials with adequate follow-up time are warranted to establish or refute our findings.

\section{Acknowledgments}

The authors thank Dana Gerberi, MLIS, Librarian, Mayo Clinic Libraries, for help with the systematic literature search.

\section{Competing interests}

Dr. Adler is a consultant for Boston Scientific.

\section{References}

[1] Kethman WHM. New approaches to gastroesophageal reflux disease. J Gastrointest Surg 2017; 21: 1544-1552

[2] Huang X, Chen S, Zhao H et al. Efficacy of transoral incisionless fundoplication (TIF) for the treatment of GERD: a systematic review with meta-analysis. Surg Endosc 2017; 31: 1032-1044

[3] Moraes-Filho JP. Refractory gastroesophageal reflux disease. Arq Gastroenterol 2012; 49: 296-301

[4] Kahrilas PJ, Howden CW, Hughes N. Response of regurgitation to proton pump inhibitor therapy in clinical trials of gastroesophageal reflux disease. Am J Gastroenterol 2011; 106: 1419-1425 quiz 1426

[5] Sheen E, Triadafilopoulos G. Adverse effects of long-term proton pump inhibitor therapy. Dig Dis Sci 2011; 56: 931-950

[6] Hunter JG, Trus TL, Branum GD et al. A physiologic approach to laparoscopic fundoplication for gastroesophageal reflux disease. Ann Surg 1996; 223: 673-685 discussion 685-677

[7] Minjarez RC, Jobe BA. Surgical therapy for gastroesophageal reflux disease. GI Motility online 2006: doi:10.1038/gimo56

[8] Singhal T, Balakrishnan S, Hussain A et al. Management of complications after laparoscopic Nissen's fundoplication: a surgeon's perspective. Ann Surg Innov Res 2009; 3: 1

[9] Smith CD, McClusky DA, Rajad MA et al. When fundoplication fails: redo? Ann Surg 2005; 241: 861-869 discussion 869-871

[10] Reynolds JL, Zehetner J, Wu P et al. Laparoscopic Magnetic sphincter augmentation vs laparoscopic Nissen fundoplication: a matched-pair analysis of 100 patients. J Am Coll Surg 2015; 221: 123-128

[11] Zadeh J, Andreoni A, Treitl D et al. Spotlight on the Linx ${ }^{\text {TM Reflux }}$ Management System for the treatment of gastroesophageal reflux disease: evidence and research. Medical devices (Auckland, NZ) 2018; 11: 291 
[12] Testoni PA, Vailati C, Testoni S et al. Transoral incisionless fundoplication (TIF 2.0) with EsophyX for gastroesophageal reflux disease: long-term results and findings affecting outcome. Surg Endosc 2012; 26: $1425-1435$

[13] Trad KS, Barnes WE, Simoni G et al. Transoral incisionless fundoplication effective in eliminating GERD symptoms in partial responders to proton pump inhibitor therapy at 6 months: the TEMPO Randomized Clinical Trial. Surg Innov 2015; 22: 26-40

[14] Stroup DF, Berlin JA, Morton SC et al. Meta-analysis of observational studies in epidemiology: a proposal for reporting. Meta-analysis Of Observational Studies in Epidemiology (MOOSE) group. JAMA 2000; 283: 2008-2012

[15] Ihde GM, Besancon K, Deljkich E. Short-term safety and symptomatic outcomes of transoral incisionless fundoplication with or without hiatal hernia repair in patients with chronic gastroesophageal reflux disease. Am J Surg 2011; 202: 740-746 discussion 746-747

[16] Ihde GM, Pena C, Scitern C et al. pH Scores in Hiatal repair with transoral incisionless fundoplication. JSLS 2019; 23: e2018.00087

[17] Janu P, Shughoury AB, Venkat K et al. Laparoscopic hiatal hernia repair followed by transoral incisionless fundoplication with EsophyX device ( $\mathrm{HH}+\mathrm{TIF})$ : efficacy and safety in two community hospitals. Surg Innov 2019; 26: 675-686

[18] Buckley FP, Bell RCW, Freeman K et al. Favorable results from a prospective evaluation of 200 patients with large hiatal hernias undergoing LINX magnetic sphincter augmentation. Surg Endosc 2018; 32: 1762-1768

[19] Czosnyka NM, Buckley FP, Doggett SL et al. Outcomes of magnetic sphincter augmentation - A community hospital perspective. Am J Surg 2017; 213: 1019-1023

[20] Rona KA, Tatum JM, Zehetner J et al. Hiatal hernia recurrence following magnetic sphincter augmentation and posterior cruroplasty: intermediate-term outcomes. Surg Endosc 2018; 32: 3374-3379

[21] Stang A. Critical evaluation of the Newcastle-Ottawa scale for the assessment of the quality of nonrandomized studies in meta-analyses. Eur J Epidemiol 2010; 25: 603-605

[22] Schwameis K, Nikolic M, Morales Castellano DG et al. Results of magnetic sphincter augmentation for gastroesophageal reflux disease. World J Surg 2018; 42: 3263-3269

[23] Bell RC, Barnes WE, Carter B] et al. Transoral incisionless fundoplication: 2-year results from the prospective multicenter U.S. study. Am Surg 2014; 80: 1093-1105

[24] Barnes WE, Hoddinott KM, Mundy S et al. Transoral incisionless fundoplication offers high patient satisfaction and relief of therapy-resistant typical and atypical symptoms of GERD in community practice. Surg Innov 2011; 18: 119-129

[25] Stefanidis G, Viazis N, Kotsikoros N et al. Long-term benefit of transoral incisionless fundoplication using the esophyx device for the management of gastroesophageal reflux disease responsive to medical therapy. Dis Esophagus 2017; 30: 1-8

[26] Bell R, Lipham J, Louie B et al. Laparoscopic magnetic sphincter augmentation versus double-dose proton pump inhibitors for management of moderate-to-severe regurgitation in GERD: a randomized controlled trial. Gastrointest Endosc 2019; 89: 14-22.e11

[27] Hunter JG, Kahrilas PJ, Bell RC et al. Efficacy of transoral fundoplication vs omeprazole for treatment of regurgitation in a randomized controlled trial. Gastroenterology 2015; 148: 324-333.e325

[28] Trad KS, Barnes WE, Prevou ER et al. The TEMPO trial at 5 years: transoral fundoplication (TIF 2.0) is safe, durable, and cost-effective. Surg Innov 2018; 25: 149-157

[29] Louie BE, Smith CD, Smith CC et al. Objective evidence of reflux control after magnetic sphincter augmentation: one year results from a post approval study. Ann Surg 2019; 270: 302-308
[30] Riegler M, Schoppman SF, Bonavina L et al. Magnetic sphincter augmentation and fundoplication for GERD in clinical practice: one-year results of a multicenter, prospective observational study. Surg Endosc 2015; 29: 1123-1129

[31] Wilson EB, Barnes WE, Mavrelis PG et al. The effects of transoral incisionless fundoplication on chronic GERD patients: 12 -month prospective multicenter experience. Surg Laparosc Endosc Percutan Tech 2014; 24: 36-46

[32] Glenny AM, Altman DG, Song F et al. Indirect comparisons of competing interventions. Health Technol Assess 2005; 9(26): 1-134 iii-iv

[33] DerSimonian R, Laird N. Meta-analysis in clinical trials. Control Clin Trials 1986; 7: 177-188

[34] Sutton AJ AK, Jones DR et al. Methods for meta-analysis in medical research. New York: J Wiley; 2000

[35] Higgins JP, Thompson SG, Spiegelhalter DJ. A re-evaluation of random-effects meta-analysis. J R Stat Soc Ser A Stat Soc 2009; 172: 137-159

[36] Mohan BP, Adler DG. Heterogeneity in systematic review and metaanalysis: how to read between the numbers. Gastrointest Endosc 2019; 89: 902-903

[37] Higgins JP, Thompson SG, Deeks JJ et al. Measuring inconsistency in meta-analyses. BMJ 2003; 327: 557-560

[38] Duval S, Tweedie R. Trim and fill: a simple funnel-plot-based method of testing and adjusting for publication bias in meta-analysis. Biometrics 2000; 56: 455-463

[39] Rothstein HR, Sutton AJ, Borenstein M. Publication bias in meta-analysis: Prevention, assessment and adjustments. John Wiley \& Sons; 2006

[40] Asti E, Bonitta G, Lovece A et al. Longitudinal comparison of quality of life in patients undergoing laparoscopic Toupet fundoplication versus magnetic sphincter augmentation: Observational cohort study with propensity score analysis. Medicine (Baltimore) 2016; 95: e4366

[41] Ganz RA, Edmundowicz SA, Taiganides PA et al. Long-term outcomes of patients receiving a magnetic sphincter augmentation device for gastroesophageal reflux. Clin Gastroenterol Hepatol 2016; 14: 671677

[42] Smith CD, DeVault KR, Buchanan M. Introduction of mechanical sphincter augmentation for gastroesophageal reflux disease into practice: early clinical outcomes and keys to successful adoption. J Am Coll Surg 2014; 218: 776-781

[43] Reynolds JL, Zehetner J, Nieh A et al. Charges, outcomes, and complications: a comparison of magnetic sphincter augmentation versus laparoscopic Nissen fundoplication for the treatment of GERD. Surg Endosc 2016; 30: 3225-3230

[44] Warren HF, Reynolds JL, Lipham JC et al. Multi-institutional outcomes using magnetic sphincter augmentation versus Nissen fundoplication for chronic gastroesophageal reflux disease. Surg Endosc 2016; 30: 3289-3296

[45] Toomey P, Teta A, Patel K et al. Transoral incisionless fundoplication: is it as safe and efficacious as a Nissen or Toupet fundoplication? Am Surg 2014; 80: 860-867

[46] Rinsma NF, Smeets FG, Bruls DW et al. Effect of transoral incisionless fundoplication on reflux mechanisms. Surg Endosc 2014; 28: 941949

[47] Håkansson B, Montgomery M, Cadiere GB et al. Randomised clinical trial: transoral incisionless fundoplication vs. sham intervention to control chronic GERD. Aliment Pharmacol Ther 2015; 42: 1261-1270

[48] Hoppo T, Immanuel A, Schuchert M et al. Transoral incisionless fundoplication 2.0 procedure using Esophy $\mathrm{X}^{\mathrm{TM}}$ for gastroesophageal reflux disease. J Gastrointest Surg 2010; 14: 1895-1901

[49] Petersen RP, Filippa L, Wassenaar EB et al. Comprehensive evaluation of endoscopic fundoplication using the EsophyX $\mathrm{X}^{\mathrm{TM}}$ device. Surg Endosc 2012; 26: 1021-1027 
[50] Witteman BP, Conchillo JM, Rinsma NF et al. Randomized controlled trial of transoral incisionless fundoplication vs. proton pump inhibitors for treatment of gastroesophageal reflux disease. Am J Gastroenterol 2015; 110: 531-542

[51] Raza A, Catalano M, Rahimi EF et al. Efficacy and safety of trans-oral incisionless fundoplication performed by gastroenterologists: 1221 . Am J Gastroenterol 2018; 113: S698-S700

[52] Ebright MI, Sridhar P, Litle VR et al. Endoscopic Fundoplication: effectiveness for controlling symptoms of gastroesophageal reflux disease. Innovations (Phila) 2017; 12: 180-185

[53] Testoni PA, Testoni S, Distefano G et al. Transoral incisionless fundoplication with EsophyX for gastroesophageal reflux disease: clinical efficacy is maintained up to 10 years. Endosc Int Open 2019; 7: E647E654
[54] Velanovich V, Vallance SR, Gusz JR et al. Quality of life scale for gastroesophageal reflux disease. J Am Coll Surg 1996; 183: 217-224

[55] Fernando HC. Endoscopic fundoplication: patient selection and technique. J Vis Surg 2017; 3: 121

[56] Guidozzi N, Wiggins T, Ahmed AR et al. Laparoscopic magnetic sphincter augmentation versus fundoplication for gastroeso112phageal reflux disease: systematic review and pooled analysis. Dis Esophagus 2019: Volume 32, Issue 9, September 2019, doz031 doi:10.1093/dote/doz031

[57] Chang CG, Thackeray L. Laparoscopic hiatal hernia repair in $221 \mathrm{pa}-$ tients: outcomes and experience. JSLS 2016; 20: e2015.00104 